\title{
Metabolic consequences of intestinal parasitism
}

\author{
BY JOHN C. MAcRAE \\ Rowett Research Institute, Bucksburn, Aberdeen AB2 9SB
}

Clinical and subclinical intestinal parasitism is characterized by impaired production (Sykes \& Coop, 1976; Steele, 1978) with poor growth rates in young animals and loss of body weight in older animals. Sheep also incur severe reductions in wool growth. A number of comprehensive reviews prepared over the last decade characterize and contrast the magnitude of such impairment across a range of intestinal roundworms and consider the factors which contribute to this problem (Armour \& Ogbourne, 1982; Bremner, 1982; Sykes, 1983; Holmes, 1986; Parkins \& Holmes, 1989; Poppi et al. 1990).

Laboratory-based experiments designed to investigate the aetiology of different infections have followed two distinct approaches. They have involved administration of either a massive single dose of parasite larvae (e.g. 30 000-100 000; Steele, 1972; Roseby, 1973), or smaller doses of larvae given daily, or perhaps two to three times per week, in a so-called 'trickle infection' approach (Sykes \& Coop, 1976; Jones \& Symons, 1982). The latter regimen was adopted to more closely simulate the way animals incur infestation under practical conditions and it has provided a clearer picture of the aetiology and the subsequent immunological resistance which accompanies any subclinical condition. It has also shown the way in which the severity of infection relates to dose rate of larvae and nutritional state of the animal.

As the present review will address mainly the metabolic consequences of subclinical parasitism, it will relate predominantly to experimental data obtained from animals subjected to 'trickle infection', mainly with the intestinal roundworm Trichostrongylus colubriformis, where very few clinical symptoms other than parasite eggs in the faeces and high eosinophil counts in the blood are seen.

\section{THE TIME-COURSE OF INFECTION}

Most studies have adopted larval dosing procedures which continue for 14-15 weeks (Sykes \& Coop, 1976; MacRae et al. 1982; Poppi et al. 1986); however, Kimambo et al. (1988a) dosed lambs daily with $T$. colubriformis larvae for 34 weeks. The growth rates of these animals and of non-parasitized control lambs pair-fed are shown in Fig. 1. These findings confirmed the earlier findings (e.g. Sykes \& Coop, 1976; Poppi et al. 1986) that from weeks 4-14 of dosing infected animals underwent a severe growth check. After this period, however, growth restarted in the infected (now resistant) animals. Faecal egg numbers increased from week 3 , peaked between weeks 7 and 8 , and decreased to negligible levels by weeks $12-14$ of dosing. Blood eosinophil counts which, at least in part, arise from IgE activation of serosal mast cells (Lewis \& Austin, 1981) increased steadily from weeks 4-5, peaked at weeks 12-16 of dosing, but stayed at significant levels thereafter, confirming the development of the immunity. Kimambo et al. (1988b) then rested the animals for 6 months following the 34-week dosing before rechallenging them with the same numbers of daily larvae for a further 10 weeks. The animals showed no detectable effects of this subsequent challenge, except for a very rapid rise in blood eosinophils showing resistance had been retained over the rest period. 

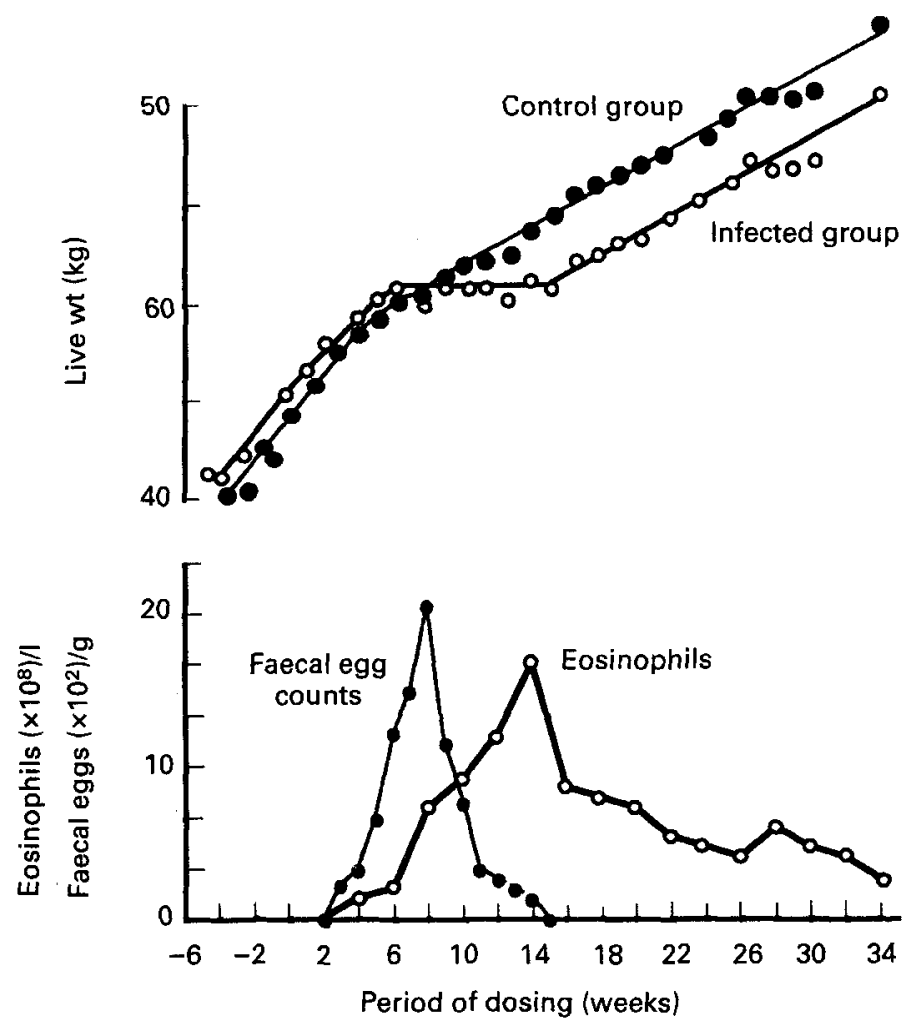

Fig. 1. Growth curves of lambs ( $n$ 5) dosed daily with 2500 Trichostrongylus colubriformis larvae for 34 weeks and of pair-fed control animals $\left(n\right.$ ). Also shown are the faecal egg counts (no. of eggs $\left.\times 10^{2}\right) / \mathrm{g}$ and blood eosinophil concentrations $\left(\times 10^{8}\right) /$ of the infected animals. (From values of Kimambo et al. 1988a.)

Most of the studies which report the effects of infection on digestive and/or metabolic function relate to the primary infection period between weeks 4 and 14 of dosing. During this period the majority of infections involve some loss of appetite, e.g. the pair-fed control animals had a 50\% reduction in live-weight gain in Fig. 1 (Kimambo et al. 1988a), but this cannot explain fully the lower growth rate or the reduction in wool growth (Symons, 1985). In consequence, considerable attention has focused on the digestive and metabolic consequences which contribute to this loss of production.

\section{ENERGY METABOLISM OF INFECTED ANIMALS}

Early findings on subclinical $T$. colubriformis infections (animals given 2500 larvae/d for 15 weeks) indicated little effect on digestibility but a reduction in the efficiency of utilization of both energy and nitrogen (Sykes \& Coop, 1976). Subsequent studies, however, using respiration chambers to determine energy expenditures in infected and pair-fed control animals indicated a significant reduction in the digestibility of the ration and, hence, in the metabolizable energy (ME) available to the infected animal between weeks 2 and 12 of dosing. Regression of energy expenditure $v$. ME intake indicated the 


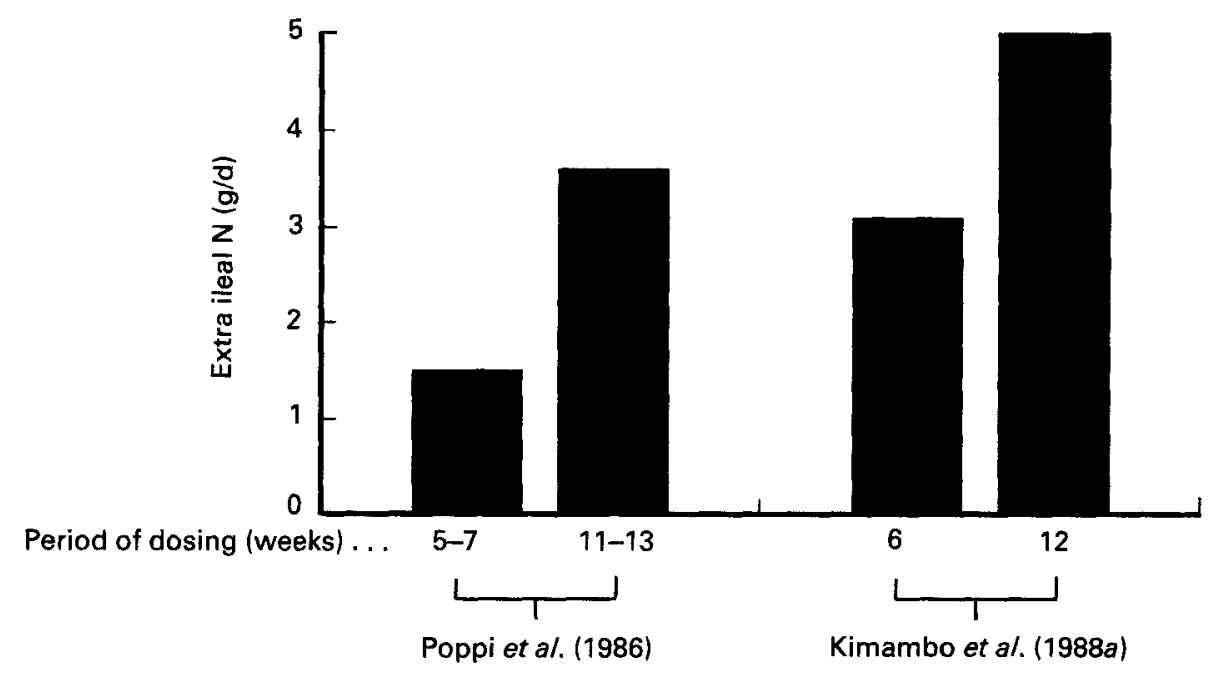

Fig. 2. Increased flow of nitrogen at the terminal ileum of lambs dosed with Trichostrongylus colubriformis (2500 g larvae/d).

relationship for the infected animals was indistinguishable from that of the pair-fed control lambs (MacRae et al. 1982).

\section{PROTEIN METABOLISM OF INFECTED ANIMALS}

The reduction in metabolizability of the ration was concomitant with a much more serious problem relating to the $\mathrm{N}$ and $\mathrm{P}$ metabolism of the infected animals. The $\mathrm{N}$ balance of infected lambs was 3-4 g N/d less than that of the pair-fed control lambs and blood $\mathrm{P}$ concentrations were approximately $50 \%$ of normal.

Using cannulation techniques to determine digesta flow, Poppi et al. (1986) found that the amount of $\mathrm{N}$ at the terminal ileum of infected animals was significantly elevated $(P<0.05)$ during weeks 5-7 and 11-13 of dosing (see Fig. 2). This was later confirmed by Kimambo et al. (1988a) (see Fig. 2). To test whether this was the result of either a reduced capacity to digest and absorb protein within the small intestines or enhanced secretion of endogenous $\mathrm{N}$ components into the lumen, Poppi et al. (1986) infused ${ }^{35} \mathrm{~S}$-labelled microbial protein into the abomasum and ${ }^{51} \mathrm{CrCl}_{3}$-labelled plasma protein into the circulation. They concluded that the major factor was probably sloughed epithelial cells, and mucin secretion, which was estimated as elevated $42-150 \%$ depending on the resorbability of these desquamated and secreted proteins; the findings showed no change in absorption of ${ }^{35} \mathrm{~S}$-labelled amino acids and although plasma leakage was elevated by $1-2 \mathrm{~g} \mathrm{~N} / \mathrm{d}$ this was assumed to be largely resorbed before the terminal ileum.

Kimambo et al. (1988a) made similar observations during weeks 6 and 12 of dosing, but the effect was reduced by week 18 and had virtually disappeared by weeks 28-33 of dosing. Interestingly, when subsequently Kimambo et al. (1988b) rechallenged their rested sheep for 10 weeks, no digestive or metabolic problems associated with the rechallenge could be detected. 


\section{PHOSPHORUS METABOLISM OF INFECTED ANIMALS}

A major consequence of intestinal parasitism appears to be a reduced absorption of $P$ from the small intestine (Wilson \& Field, 1983; Poppi et al. 1985; Bown et al. 1989), leading to reduced bone formation, low plasma $\mathrm{P}$ levels and reduced salivary $\mathrm{P}$ secretions. The reasons for this in sheep dosed with $T$. colubriformis larvae are not fully understood, but may relate to the reduced intestinal motility in the upper regions of the duodenum (Gregory et al. 1985) and the consequent precipitation of digesta $\mathrm{P}$ out of solution, as $\mathrm{Ca}$ and $\mathrm{Mg}$ complexes, at $\mathrm{pH}$ 6-8 in the upper small intestine (Poppi $e$ t al. 1985). Low $P$ absorption and the consequent low salivary $P$ secretion has been linked to inappetence in sheep (Field et al. 1975; Milton \& Ternouth, 1982) and indeed most experimentally-induced parasitisms induce varying degrees of anorexia. However, the major effect of the failure to absorb P (Poppi et al. 1985) is to severely impair bone mineralization which results in the characteristic stunted skeletal development of infected animals.

\section{CONSEQUENCES OF THE PRIMARY INFECTION ON GASTROINTESTINAL (GI)}

\section{TRACT PROTEIN METABOLISM}

In order to consider the consequences of the presence of the parasites in the GI tract on the metabolic functioning of the tract and of other organs and tissues, it is first necessary to consider the complexity of protein metabolism within the different body components in the normal animal. Lobley et al. (1980) identified the disparity between the proportional distribution of protein mass in different body components of cattle and the corresponding rates of protein synthesis. Thus, whereas skeletal muscle, which represents $45 \%$ of protein mass, accounts for only $16-22 \%$ of total whole-body protein synthesis, the GI tract, which comprises only $5 \%$ of total protein, contributes $25-45 \%$ to total synthesis. These distributions are similar in young sheep (Attaix et al. 1987) and when allied with rates of protein deposition in animals of similar growth (J. C. MacRae, unpublished results) a general picture of the relative protein turnovers which occur in a number of body components in the lamb can be compiled (see Fig. 3).

Broadly, tissues can be divided into two distinct types in the growing animal. First, in tissues such as skeletal muscle (and skin) protein degradation proceeds at only $60-70 \%$ of synthesis and, thus, approximately $30-40 \%$ of the protein which the tissues synthesize is accreted. Such peripheral tissues may be considered as 'protein stores'. In other tissues, however, such as the GI tract and the liver, the rates of synthesis and degradation are greater with only low net accretion (but considerable production of export protein). In the case of the weaned lamb the GI tract accounts for $0.27(77 \mathrm{~g} / \mathrm{d})$ of the whole-body protein synthesis yet net accretion is only $1 \mathrm{~g}$ protein/d. Thus, $76 \mathrm{~g}$ of the protein are degraded and/or secreted.

The representation in Fig. 3 of the degraded GI tract protein recycling directly back to the body amino acid pool is, therefore, oversimplistic and the structure of the tissue needs to be considered. The proteins of the GI tract comprise two distinct types, those of the serosa involved in propulsion of digesta through the tract and those of the mucosal epithelia which assist in nutrient absorption. The mucosal cells are continuously differentiated in the crypt regions of the epithelium and then migrate to the tips of the villi over a period of 36-48 $\mathrm{h}$ where they are desquamated into the lumen. Whilst the simple recycling concept illustrated in Fig. 3 could apply to the serosal proteins, a 


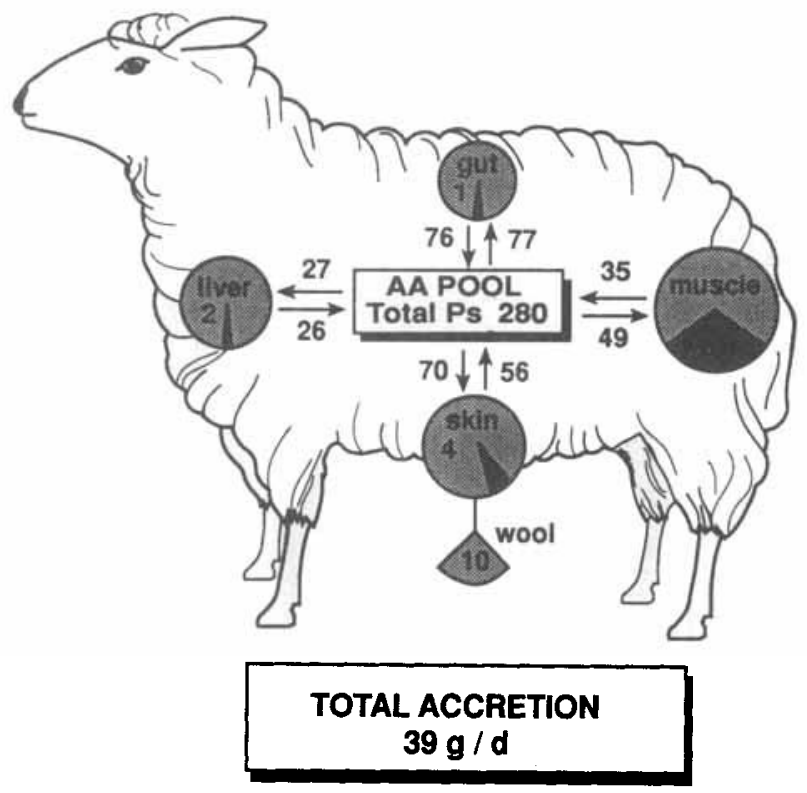

Fig. 3. Protein turnover (g/d) in different body components of young weaned lambs (calculated from values of Attaix et al. (1987) and J. C. MacRae (unpublished results).

considerable proportion of the mucosal proteins, along with the digestive secretions and mucins require redigestion to amino acids and resorption of these before they are again available to the body. The efficiency of this salvage process is difficult to determine, but is not qualitative since Bown et al. (1986) estimated resorption of plasma proteins at $85 \%$, while only $70 \%$ of ${ }^{35} \mathrm{~S}$-labelled microbial protein introduced into the tract is recovered (Poppi et al. 1986). The unresorbed residues will enter the large intestine and be excreted either in the faeces or, if sufficient energy is available for secondary microbial fermentation, via the urine as urea following ammonia release in the hind-gut, absorption and hepatic ureogenesis. Either way, this loss is detrimental to the $\mathrm{N}$ economy of the animal.

If the redigestion/resorption efficiency remains constant then the magnitude of the 'leakiness' or net loss will be proportional to the rate of intestinal protein synthesis. This rate has been shown to be influenced by physiological and nutritional state, e.g. the transition at weaning increased the rate of GI tract protein synthesis in lambs from 49 to $77 \mathrm{~g} / \mathrm{d}$ (Attaix et al. 1987). No direct measurements have been reported of the rates of GI tract protein synthesis during the primary infection phase of parasitism in farm animals, but in guinea-pigs infected with $T$. colubriformis the rate of small intestine protein synthesis increased by $10 \%(P<0.06)$ in the first third (the main area of infection) and by $40 \%(P<0.001)$ in the section distal to this region. The enhanced flow of $\mathrm{N}$ into the large intestine, as indicated in Fig. 2, is clear evidence that excess leakage results from this increased turnover of cellular proteins plus, probably, enhanced intestinal secretions of mucin and/or digestive enzymes. 


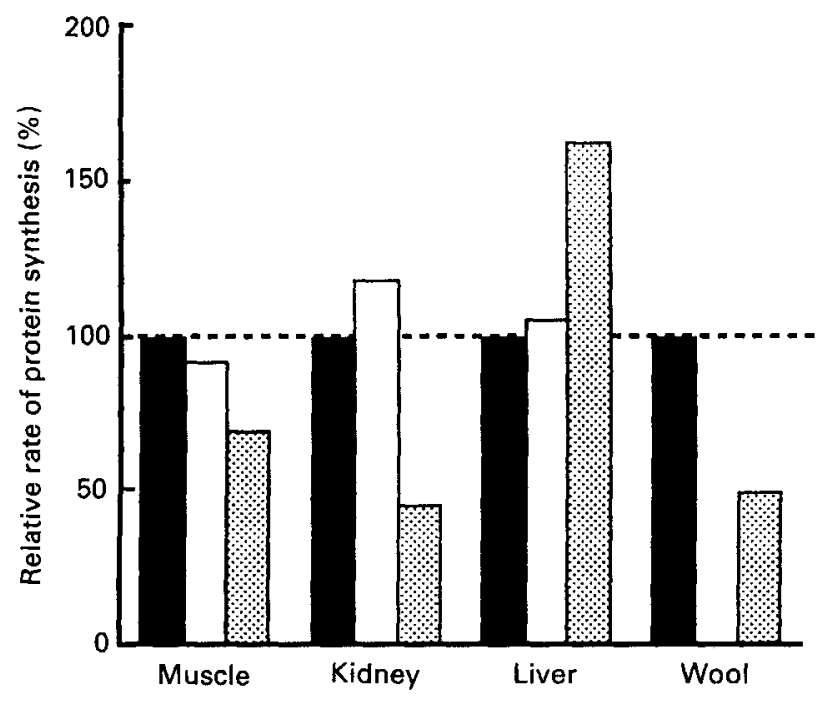

Fig. 4. Relative rates of protein synthesis in skeletal muscle, liver, kidney and wool of ad lib.-fed control sheep (四; 100\%), sheep infected with Trichostrongylus colubriformis (国) and sheep pair-fed to the intake of the infected animals ( $\square$ ). From values of Symons \& Jones (1975) and Jones \& Symons (1982).

\section{CONSEQUENCES OF THE PRIMARY INFECTION ON THE PROTEIN METABOLISM OF OTHER TISSUES}

Increased protein and amino acid loss via the GI tract will reduce the amount available for other tissues. Symons \& Jones (1975) and Jones \& Symons (1982) found lowered rates of protein synthesis in skeletal muscle, liver and wool of sheep infected with $T$. colubriformis, compared with control animals fed ad lib. (Fig. 4). These were mainly the result of inappetence, but even relative to pair-fed controls the rates in muscle, kidney and skin were still markedly reduced. Liver values were more equivocal, the incorporation of tritium-labelled leucine being higher per unit RNA and DNA in the infected animals $(P=0.06$ and $P=0.055$ respectively). The technique employed would underestimate serum protein synthesis which would need to be enhanced both to offset the extra leakage into the intestine and to contribute to the immunological resistance which develops in these animals. However, these findings substantiate previous reports in guinea-pigs and in mice infected with $T$. colubriformis or $N$. dubius (Symons \& Jones, 1971) and helped explain the observations of Sykes \& Coop (1976) that the protein content of body tissue gain is considerably reduced in infected animals, from 114 and 124 $\mathrm{g} / \mathrm{kg}$ live-weight gain in ad lib.- and pair-fed control animals respectively to $80 \mathrm{~g} / \mathrm{kg}$ live-weight gain in infected animals.

Thus, the overall metabolic consequence of the intestinal infection seems to involve the diverting of protein synthesis away from muscle and bone (the 'storage' tissues) and towards the repair, replacement and reaction to damage of the gut wall, to mucus production and to plasma or whole blood loss. 


\section{CONSEQUENCES OF INFECTION ON THE AVAILABILITY OF INDIVIDUAL AMINO ACIDS FOR TISSUE PROTEIN SYNTHESIS}

The aforementioned penalties may be exacerbated by alterations in the supply of individual amino acids. The amino acid composition of material absorbed from the small intestine is similar to mixed muscle protein, but is different from digestive secretions such as proteolytic enzymes and mucin, especially for valine, threonine, serine and proline (MacRae \& Lobley, 1991). Thus, any elevation in digestive secretion losses will decrease the availability of these amino acids for protein synthesis and gain in other tissues. Most serious is the high concentration of threonine $(280 \mathrm{mmol} / \mathrm{mol})$, serine $(130 \mathrm{mmol} / \mathrm{mol})$ and proline $(130 \mathrm{mmol} / \mathrm{mol}$ ) in intestinal mucus (Neutra \& Forstner, 1987), which is reported to be resistant to proteolytic degradation and poorly resorbed from the small intestine (Lindsay et al. 1980).

Another implication of the immunological resistance phase of infection relates to the availability of sulphur-amino acids for leukotriene production (Lewis \& Austen, 1981). These compounds are thought to be involved in the ability of the host animal to impede larval development through inhibition of smooth muscle contraction and paralysis of larvae. Douch et al. (1983) first observed the larval migration inhibitory properties of mucus from sheep resistant to $T$. colubriformis larvae and identified that the factor responsible had properties similar to the slow-reacting substance of anaphylaxis (SRS-A). The major constituents of SRS-A are the cysteine-rich leukotrienes $\mathrm{LTC}_{4}$, $\mathrm{LTD}_{4}$ and $\mathrm{LTE}_{4}$ thought to be produced from arachidonic acid by serosal cells following IgE activation of mast cells (Lewis \& Austen, 1981). Kimambo \& MacRae (1988) subsequently detected this same migration inhibitory factor in abomasal and intestinal mucosa of resistant animals, and also in the ileal digesta during larval challenge. Each of these leukotrienes contains a cysteine residue and if produced in greater quantity during the development and maintenance of immunological resistance this could reduce the net availability of this sulphur-amino acid for other tissues.

Interestingly, Barger et al. (1973) observed that sheep resistant to $T$. colubriformis produce $17-18 \%$ less wool when subjected to a larval challenge; wool is rich in cysteine (10\% of the total amino acid mixture, approximately fourfold higher than that in most other body components; see MacRae \& Lobley, 1991). Also, in the experiments of Kimambo et al. (1988a), once the lambs had developed resistance they started to regain weight, but, although they received the same quantity of feed daily as the pair-fed controls which were several kilograms heavier, the resistant animals exhibited no catch-up growth, implying some kind of nutritional penalty associated with their immunological status.

\section{NUTRITIONAL SUPPLEMENTATION}

It follows from the previously described considerations that amino acid supply for protein gain in the storage organs, such as muscle, bone and skin (wool), is severely restricted during the primary infection phase of parasitism and this may continue for specific amino acids in the immunologically-resistant animal. It is not surprising, therefore, that where animals have received supplemental protein, either by increasing the protein:energy value of the diet (Abbott et al. 1988), or by infusion of protein into the abomasum (Bown et al. 1986), this has reduced faecal output and worm burdens, 
enhanced the onset of immunity, and offset the growth check associated with Haemonchus contortus (Abbott et al. 1988) and T. colubriformis (Bown et al. 1986) infections (see Holmes, 1986).

While it may appear less probable that $\mathrm{P}$ supplementation will increase the availability to tissues since the ability to absorb $\mathrm{P}$ is impaired by infection (Wilson \& Field, 1983; Poppi et al. 1985), Coop \& Field (1973) were able to increase live-weight gain in parasitized animals by increasing the $P$ content of the diet from 1.9 to $2.7 \mathrm{~g} / \mathrm{kg}$ dry matter. They observed also a possible enhancement of the host immune response on the higher $\mathbf{P}$ diet in that at slaughter, after 14 weeks of infection, worm burdens were reduced from 11000 on the low-P diet to 1250 on the high-P diet.

\section{CONCLUSIONS}

Intestinal parasitism diverts amino acids towards protein metabolism in the GI tract and this has major consequences for other organs and tissues. The inefficient absorption of enhanced digestive secretions, particularly mucus, and sloughed mucosal proteins represents a net drain on the $\mathrm{N}$ economy of the host animal and may cause amino acid imbalances. Impaired $P$ absorption inhibits bone mineralization and may induce inappetence in infected animals. Supplementation of diets with protein and $P$ appears to offset the growth check and may also enhance the onset of the immunological resistance in infected animals.

\section{REFERENCES}

Abbott, E. M., Parkins, J. J. \& Holmes, P. H. (1988). Influence of dietary protein on the pathophysiology of haemonchosis in lambs given continuous infections. Research in Veterinary Science 45, 41-49.

Armour, J. \& Ogbourne, C. P. (1982). Bovine ostertagiasis: a review and annotated bibliography. Commonwealth Institute of Parasitology Miscellaneous Publication no. 7. Farnham Royal: Commonwealth Agricultural Bureaux.

Attaix, D., Aurousseau, E., Bayle, G., Manghebate, A. \& Arnal, M. (1987). Protein synthesis and degradation in growing lambs. In Protein Metabolism and Nutrition, European Association of Animal Production Publication no. 32, pp. 24-27. ZWPU, Rostock: Wiss.

Barger, I. A., Southcote, W. H. \& Williams, B. J. (1973). Trichostrongylus and wool growth. 2. The wool growth response of infected sheep to parenteral and duodenal cystine and cysteine supplementation. Australian Journal of Experimental Agriculture and Animal Husbandry 13, 351-359.

Bown, M. D., Poppi, D. P. \& Sykes, A. R. (1986). The effect of postruminal infusion of protein or energy on the pathology of Trichostrongylus colubriformis infection and body composition in lambs. Proceedings of the New Zealand Society of Animal Production 46, 27-30.

Bown, M. D., Poppi, D. P. \& Sykes, A. R. (1989). The effect of a concurrent infection of Trichostrongylus colubriformis and Ostertagia circumcincta on calcium, phosphorus and magnesium transactions along the digestive tract of lambs. Journal of Comparative Pathology 101, 11-20.

Bremner, K. C. (1982). The pathophysiology of parasitic gastroenteritis of cattle. In Biology and Control of Endoparasites. Proceedings of the Animal Health Laboratory 50th Annual Symposium in Parasitology, pp. 277-289 [L. E. A. Symons, A. D. Donald and J. K. Dineen, editors]. New York: Academic Press.

Coop, R. L. \& Field, A. C. (1973). The effect of phosphorus intake on growth rate, food intake and quality of the skeleton of growing lambs infected with the intestinal nematode Trichostrongylus vitrinus. Research in Veterinary Science 35, 175-181.

Douch, P. G. C., Harrison, G. B. L., Buchanan, L. L. \& Greer, K. S. (1983). In vitro bioassay of sheep gastrointestinal mucus for nematode paralysing activity mediated by substances with some properties characteristic of SRS-A. International Journal of Parasitology 13, 207-212.

Field, A. C., Suttle, N. F. \& Nisbet, D. I. (1975). The effects of diets low in calcium and phosphorus on the development of growing lambs. Journal of Agricultural Science, Cambridge 85, 435-442. 
Gregory, P. C., Wenham, G., Poppi, D., Coop, R. L., MacRae, J. C. \& Miller, S. J. (1985). The influence of a chronic subclinical infection of Trichostrongylus colubriformis on gastrointestinal motility and digesta flow in sheep. Parasitology 91, 381-396.

Holmes, P. H. (1986). Pathophysiology of nematode infections. In Proceedings of the 6th International Congress of Parasitology [M. J. Howell, editor]. Canberra, Australia: Academy of Science.

Jones, W. O. \& Symons, L. E. A. (1982). Protein synthesis in the whole body, liver, skeletal muscle and kidney cortex of lambs infected by the nematode Trichostrongylus colubriformis. International Journal of Parasitology 12, 295-301.

Kimambo, A. E. \& MacRae, J. C. (1988). Measurement in vitro of a larval migration inhibitory factor in gastrointestinal mucus of sheep made resistant to the roundworm Trichostrongylus-colubriformis. Veterinary Parasitology 28, 213-222.

Kimambo, A. E., MacRae, J. C. \& Dewey, P. J. S. (1988b). Effect of daily challenge with Trichostrongylus colubriformis larvae on the nutrition and performance of immunologically-resistant sheep. Veterinary Parasitology 28, 205-212.

Kimambo, A. E., MacRae, J. C., Walker, A., Watt, C. F. \& Coop, R. L. (1988a). The effect of prolonged subclinical infection with Trichostrongylus colubriformis on the performance and nitrogen metabolism of growing lambs. Veterinary Parasitology 28, 191-203.

Lewis, R. A. \& Austen, K. F. (1981). Mediation of local homeostasis and inflammation by leukotrienes and other master cell-dependent compounds. Nature 293, 103-108.

Lindsay, J. R., Hogan, J. P. \& Donnelly, J. B. (1980). The digestion of protein from forage diets in the small intestines of the sheep. Australian Journal of Agricultural Research 31, 589-600.

Lobley, G. E., Milne, V., Lovie, J. M., Reeds, P. J. \& Pennie, K. (1980). Whole-body and tissue protein synthesis in cattle. British Journal of Nutrition 54, 681-694.

MacRae, J. C. \& Lobley, G. E. (1991). Physiological and metabolic implications of conventional and novel methods for the manipulation of growth and production. Livestock Production Science 27, 43-59.

MacRae, J. C., Smith, J. S., Sharman, G. A. M., Corrigall, W. \& Coop, R. L. (1982). Energy metabolism of lambs infected with Trichostrongylus colubriformis. In Energy Metabolism of Farm Animals. European Association of Animal Production Publication no. 29, pp. 112-115 [A. Ekern and F. Sundstol, eđitors]. Aas, Norway: The Agricultural University of Norway.

Milton, J. T. B. \& Ternouth, J. H. (1982). The site of the effect of phosphorus deficiency upon food intake. Proceedings of the Australian Society of Animal Production 41, 630.

Neutra, M. R. \& Forstner, J. M. (1987). Gastrointestinal mucus: synthesis, secretion and function. In Physiology of the Gastrointestinal Tract, vol. 2, 2nd ed., pp. 975-1009 [L. R. Johnson, editor]. New York: Raven Press.

Parkins, J. J. \& Holmes, P. H. (1989). The effects of gastrointestinal helminths of parasites on ruminant nutrition. Nutrition Research Reviews 2, 227-246.

Poppi, D. P., MacRae, J. C., Brewer, A. \& Coop, R. L. (1986). Nitrogen transactions in the digestive tract of lambs exposed to the intestinal parasite Trichostrongylus colubriformis. British Journal of Nutrition 55, 593-602.

Poppi, D. P., MacRae, J. C., Brewer, A. C., Dewey, P. J. S. \& Walker, A. (1985). Calcium and phosphorus absorption in lambs exposed to Trichostrongylus colubriformis. Journal of Comparative Pathology 95, $453-464$.

Poppi, D. P., Sykes, A. R. \& Dynes, R. A. (1990). The effect of endoparasitism on host nutrition - the implications for nutrient manipulation. Proceedings of the New Zealand Society of Animal Production $\mathbf{5 0}$, $237-243$.

Roseby, F. V. (1973). Effects of Trichostrongylus colubriformis (Nematoda) on the nutrition and metabolism of sheep. 1. Feed intake digestion and utilisation. Australian Journal of Agricultural Research 24, 942-953.

Steele, J. W. (1972). The effects of the intestinal nematode Trichostrongylus colubriformis on ruminal acetate metabolism in young sheep. Proceedings of the Australian Society of Animal Production 9, 402-407.

Steele, J. W. (1978). Interrelationships between gastrointestinal helminth infection, nutrition and impaired productivity in the ruminant. In Recent Advances in Animal Nutrition, pp. 98-109 [D. J. Farrell, editor]. Armidale, NSW: University of New England Printing Unit.

Sykes, A. R. (1983). Effects of parasitism on metabolism in the sheep. In The Sheep Production. Nottingham Easter School of Agricultural Science no. 35, pp. 317-334 [W. Haresign, editor]. London: Butterworths.

Sykes, A. R. \& Coop, R. L. (1976). Intake and utilisation of food by growing lambs with parasitic damage to the small intestine caused by daily dosing with Trichostrongylus colubriformis larvae. Journal of Agricultural Science, Cambridge 86, 507-515. 
Symons, L. E. A. (1985). Anorexia: occurrence, pathophysiology and possible causes in parasitic infections. Advances in Parasitology 24, 103-133.

Symons, L. E. A. \& Jones, W. O. (1971). Protein metabolism. 1. Incorporation of ${ }^{14} \mathrm{C}$-L-leucine into skeletal muscle and liver proteins of mice and guinea pigs infected with Nematospiroides dubius and Trichostrongylus colubriformis. Experimental Parasitology 29, 230-241.

Symons, L. E. A. \& Jones, W. O. (1975). Skeletal muscle, liver and wool protein synthesis by sheep infected by the nematode Trichostrongylus colubriformis. Australian Journal of Agricultural Research 26, 10631072 .

Wilson, W. D. \& Field, A. C. (1983). Absorption and secretion of calcium and phosphorus in the alimentary tract of lambs infected with daily doses of Trichostrongylus colubriformis or Ostertagia circumcincta larvae. Journal of Comparative Pathology 93, 61-71. 